\title{
Epigenetics in the Human Brain
}

\author{
Isaac Houston ${ }^{1}$, Cyril J Peter ${ }^{1}$, Amanda Mitchell ${ }^{1}$, Juerg Straubhaar ${ }^{2}$, Evgeny Rogaev ${ }^{1}$ and \\ Schahram Akbarian ${ }^{\star, 1}$ \\ ${ }^{1}$ Brudnick Neuropsychiatric Research Institute, Department of Psychiatry, University of Massachusetts Medical School, \\ Worcester, MA, USA; ${ }^{2}$ Program in Molecular Medicine, University of Massachusetts Medical School, Worcester, \\ MA, USA
}

Many cellular constituents in the human brain permanently exit from the cell cycle during pre- or early postnatal development, but little is known about epigenetic regulation of neuronal and glial epigenomes during maturation and aging, including changes in mood and psychosis spectrum disorders and other cognitive or emotional disease. Here, we summarize the current knowledge base as it pertains to genome organization in the human brain, including the regulation of DNA cytosine methylation and hydroxymethylation, and a subset of (altogether $>100$ ) residue-specific histone modifications associated with gene expression, and silencing and various other functional chromatin states. We propose that high-resolution mapping of epigenetic markings in postmortem brain tissue or neural cultures derived from induced pluripotent cells (iPS), in conjunction with transcriptome profiling and whole-genome sequencing, will increasingly be used to define the molecular pathology of specific cases diagnosed with depression, schizophrenia, autism, or other major psychiatric disease. We predict that these highly integrative explorations of genome organization and function will provide an important alternative to conventional approaches in human brain studies, which mainly are aimed at uncovering group effects by diagnosis but generally face limitations because of cohort size.

Neuropsychopharmacology Reviews (2013) 38, 183-197; doi: I 0. 1038/npp.20 I2.78; published online 30 May 2012

Keywords: DNA methylation; DNA hydroxymethylation; post-translational histone modification; chromosome conformation; postmortem brain; psychiatric disease

\section{INTRODUCTION}

Chromatin is defined by arrays of nucleosomes, or $146 \mathrm{bp}$ of genomic DNA wrapped around an octamer of core histones, connected by linker DNA and linker histones. The combined set of covalent DNA and histone modifications and variant histones provide the major building blocks for the 'epigenome', or the epigenetic landscapes that mold and organize DNA inside a cell nucleus into myriads of transcriptional units, clusters of condensed chromatin and many other features that distinguish between various cell types and developmental stages sharing the same genome (Li and Reinberg, 2011a; Rodriguez-Paredes and Esteller, 2011). For recent updates on the complexities of the epigenetic code, including the association of various DNA and histone modification types and variant histones with promoter, enhancer, gene body, and repeat sequences, or

${ }^{*}$ Correspondence: Dr S Akbarian, Brudnick Neuropsychiatric Research Institute, Department of Psychiatry, University of Massachusetts Medical School, 303 Belmont Street, Worcester, MA 01604, USA, Tel: +1 508 8562674, Fax: + 1508 8562627, E-mail: Schahram.akbarian@mssm.edu Received 27 February 2012; revised 11 April 2012; accepted 16 April 2012 their respective role in chromatin condensation, (see Ederveen et al, 2011; Kinney et al, 2011; Zhou et al, 2011). From a broad perspective, chromatin is ultimately also the critical substrate through which genetic information and, more broadly, the genome's structural organization intersects with a (nucleated) cell's physiology in health and disease. Consequently, exploration of brain epigenomes, including localized and genome-wide regulation of various DNA methylation markings, histone modification, and variants, bears a potential to provide critical insights into the neurobiology of neurological and psychiatric disease. Although much about epigenetic (dys) regulation in CNS disorders has been learned from work conducted in preclinical model systems (see the various papers in this issue of Neuropsychopharmacology Reviews for in depth review and timely update), the number of studies focused on chromatin structure and function in normal and diseased human brain is rapidly increasing. Here, we summarize the current state of knowledge as it pertains to epigenetic regulation in the human brain, including changes during normal development and aging and potential changes in various neuropsychiatric disorders, including autism, schizophrenia, and depression. Our review will 
mention unresolved design problems as it pertains to epigenome exploration in human brain and emphasize the importance of high-resolution epigenome mapping in various neuronal and glial subtypes residing in specific anatomical areas of the human brain. We argue that chromatin studies in neural tissues, including postmortem brain and differentiated neuronal cultures derived from pluripotent skin cells and other sources, could provide the foundation for a new generation of disease models that integrate the genetic and epigenetic risk architecture of specific individuals with their molecular and cellular brain pathologies.

\section{THE BUILDING BLOCKS OF THE EPIGENOME}

\section{DNA (Hydroxy)-methylation}

Two related but functionally very different types of DNA modifications, methylation (m) and hydroxymethylation $(\mathrm{hm})$ of cytosines in $\mathrm{CpG}$ dinucleotides, are often found in CpG enriched sequences (Kriaucionis and Heintz, 2009). The mC5 and hmC5 markings show a strikingly different distribution, with hmC5 mostly confined to the $5^{\prime}$ end of genes, with levels generally correlating with gene transcription at that locus (Jin et al, 2011; Song et al, 2011). In striking contrast, only a minute portion $(<3 \%)$ of mC5 locates to the $5^{\prime}$ end of genes, thereby functioning as repressive mark. The remaining $97 \%$ of $\mathrm{mC} 5 \mathrm{~s}$ are found in intra- and intergenic sequences and within DNA repeats (Maunakea et al, 2010).

\section{Histone Modifications}

There are more than 100-amino acid residue-specific PTMs in a typical vertebrate cell (Tan et al, 2011), including mono (me1), di (me2)-, and tri (me3) methylation, acetylation and crotonylation, polyADP-ribosylation, and small protein (ubiquitin, SUMO) modification of specific lysine residues, as well as arginine (R) methylation and 'citrullination', serine (S) phosphorylation, tyrosine ( $\mathrm{T}$ ) hydroxylation, among others (Kouzarides, 2007; Tan et al, 2011; Taverna et al, 2007). These site- and residue-specific PTMs show close association with the functional architecture of chromatin, differentiating between promoters and gene bodies, enhancer and other regulatory sequences, condensed heterochromatin (Zhou et al, 2011) (Figure 1). The modifications do not occur in isolation, and instead multiple histone PTM appear to be co-regulated and, as a group define the aforementioned chromatin states. For example, both histone $\mathrm{H} 3$ lysine 4 methylation and various histone acetylation markings are upregulated at many transcription start sites of actively expressed genes (Zhou et al, 2011). Furthermore, there is also evidence for a coordinated and sequential regulation; for example, phosphorylation of histone $\mathrm{H} 3$ at the serine (S) 10 position often serves as a prelude for subsequent acetylation of neighbor- ing lysine residues $\mathrm{K} 9$ and $\mathrm{K} 14$ in the context of transcriptional activation, while at the same time blocking repression-associated methylation of $\mathrm{K} 9$ (Nowak and Corces, 2004).

\section{Histone Variants}

In addition to the core histones $\mathrm{H} 2 \mathrm{~A} / \mathrm{H} 2 \mathrm{~B} / \mathrm{H} 3 / \mathrm{H} 4$, metazoan genomes encode histone variants, such as H3.3, H2A.Z, and H2A.X (Figure 1), that in contrast to the canonical histones are subject to replication-independent expression and assembly (Woodcock, 2006), with strong effects on nucleosome stability and compaction (Jin and Felsenfeld, 2007). It is generally thought that RNA polymerase and the transcriptional activation and elongation complexes destabilize nucleosomes, promoting nucleosome remodeling, and variant histone incorporation, which then further potentiate or stabilize gene expression (Bintu et al, 2011; Sutcliffe et al, 2009).

Nucleosomes are comprised of a protein octamer of four small proteins, the core histones (see above) around which $146 \mathrm{bp}$ of DNA is wrapped around. Transcription start sites are often defined by a nucleosome-free interval, probably for increased access of the transcriptional initiation complex and other regulators of gene expression. Arrays of nucleosomes, connected by linker DNA and linker histones, comprise the $10 \mathrm{~nm}$ 'beads-on-a-string' chromatin fiber. Euchromatin defines loose chromatin typically at sites of actively transcribed genes and units poised for transcription. Heterochromatin defines tightly packed nucleosomal arrays. Constitutive heterochromatin remains highly condensed in most interphase nuclei. Examples includes pericentric and telomeric repeat DNA, the inactivated X-chromosome ('Barr body') of female somatic cells, and other chromosomal structures often found in close proximity to the nuclear envelope and also around the nucleolus (see Figure 1). Facultative heterochromatin includes silenced genes that upon differentiation or other stimuli could switch to a state of active transcription.

\section{EPIGENETICS AND TRANSCRIPTIONAL (dys) REGULATION IN DISEASED HUMAN BRAIN. A 'SUBJECT-SPECIFIC' MATTER?}

To date, epigenetic approaches in psychiatry are typically focused on gene expression alterations in brain of subjects diagnosed with psychosis or mood spectrum disorder, and other neurodevelopmental, or neurodegenerative disease. The overarching working model implies that a change in promoter DNA methylation or histone modification is a potential indicator for altered gene expression activity at that locus, which in turn is responsible for the corresponding changes in RNA levels. Such type of hypothesis became very popular in the field, because (i) psychiatric disorders typically lack a unifying neuropathology but often are defined by distinct messenger RNA level changes in cerebral 


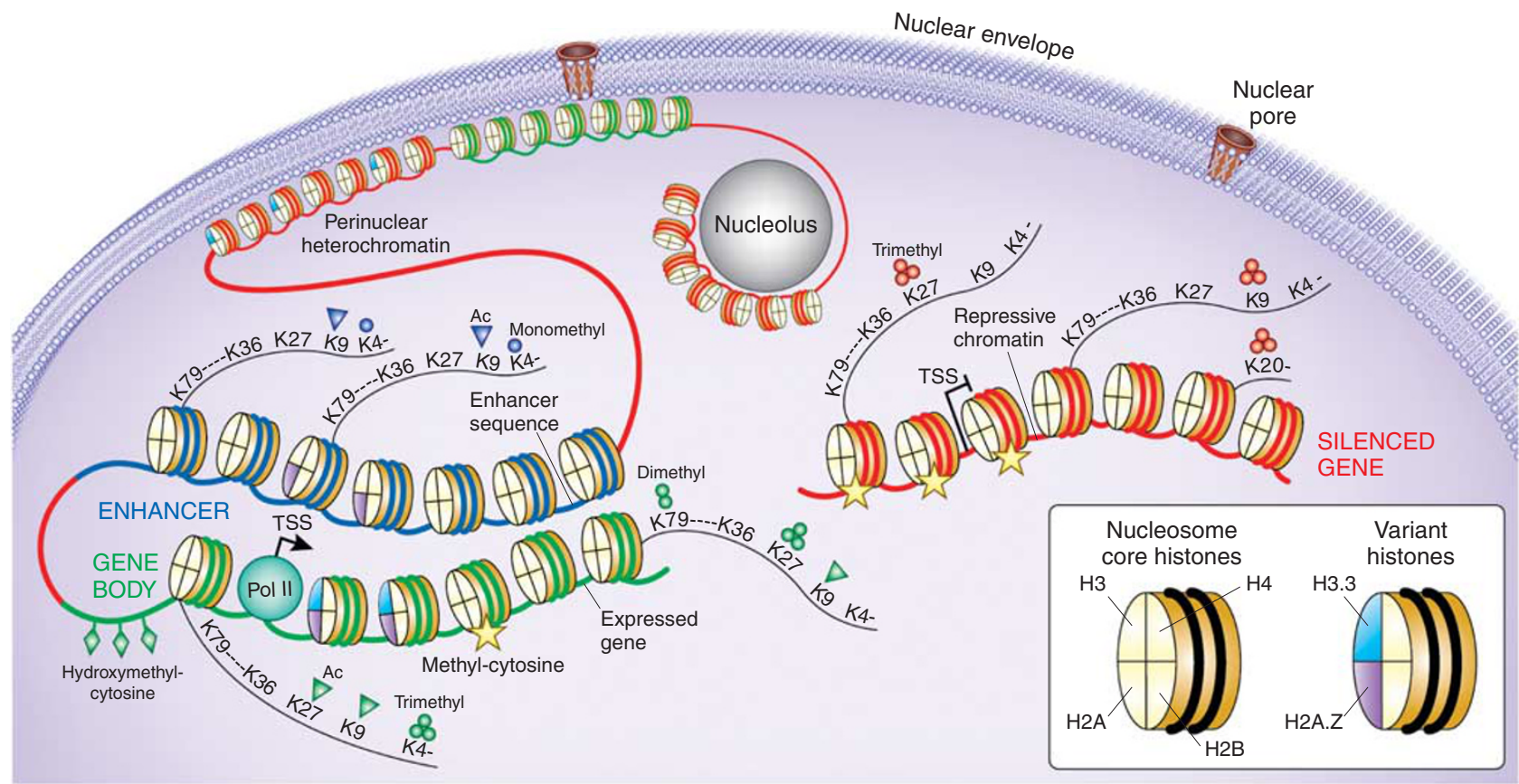

Figure 1. The Epigenome, from nucleus to nucleosome. Schematic illustration of (green) gene poised for transcription by polymerase II (Pol II) initiation complex, with nucleosome free interval at transcription start site (TSS). (Blue) distal enhancer sequence which in loop-like structure moves in close proximity to active gene. (Red) marks a small subset of heterochromatic portions of the genome, including silenced gene and heterochromatic structures bordering the nuclear envelope and pore complex, and also the nucleolar periphery. A small subset of representative histone variants and histone $\mathrm{H} 3$ site-specific lysine (K) residues at $\mathrm{N}$-terminal tail (K4, K9, K27, and K36) or core fold domain of the (histone) octamer (K79) and the H4K20 residue are shown as indicated, together with panel of mono- and trimethyl, or acetyl modifications that differentiate between active promoters, transcribed gene bodies, and repressive chromatin, as indicated. DNA cytosines that are hydroxymethylated at the C5 position are mostly found at active promoters, whereas methylated cytosines are positioned within body of actively transcribed genes and around repressed promoters and in constitutive heterochromatin.

cortex and other areas of the (postmortem) brain, affecting transcripts for inhibitory and excitatory neurotransmission, oligodendroglia and myelination, synaptic connectivity, and many other functions (Mirnics and Pevsner, 2004); (ii) RNA quantification alone was unable to provide further insights into the underlying mechanisms, and whether transcriptional $v s$ post-transcriptional regulatory mechanisms were driving the observed phenotypic differences between diseased and control brains (Gavin and Akbarian, 2011); (iii) the 'classical' model for epigenetic regulation of gene expression offering an attractive and straightforward hypothesis invoked proximal promoter sequences, with DNA methylation serving as the repressive, and histone acetylation as the facilitative signal (Sharma et al, 2005; Tsankova et al, 2007); and (iv) nucleosomal arrays, histone and DNA methylation markings and other molecular architectures inside the nucleus remain stable for a prolonged period after death and maintain a robust signal in typical postmortem brain tissue, which typically is exposed to $5-30 \mathrm{~h}$ (or more) of autolysis time before being safely stored in a $-70{ }^{\circ} \mathrm{C}$ freezer (Ernst et al, 2008; Huang et al, 2006).

Thus, more than a decade ago, epigenetic exploration of the diseased human brain started out with restrictionenzyme-based DNA cytosine methylation mapping at a predetermined set of $\mathrm{CpG}$ dinucleotides surrounding the $5^{\prime}$ end of amyloid beta precursor (Rogaev et al, 1994) and FMR1 genes in single cases diagnosed with Alzheimer's disease and fragile X-mental retardation syndrome (Tassone et al, 1999; Tohgi et al, 1999; West et al, 1995). In case of fragile $\mathrm{X}$, the expansion of CGG codon from (normally) 5-40 repeats from 50 to over 200 triggers excessive DNA methylation at the promoter, effectively shutting down gene expression by silencing the surrounding chromatin (Oberle et al, 1991). These highly reproducible molecular phenotypes in a monogenetic neurodevelopmental disorder then provided a roadmap for similar studies by pioneer investigators studying disorders of a more heterogeneous and complex etiology, including depression, schizophrenia, and others. For example, hypermethylation of the REELIN promoter (encoding a glycoprotein critically important for neuronal migration and connectivity formation) (Abdolmaleky et al, 2005; Grayson et al, 2005), and hypomethylation of catechyl-O-methyltransferase (COMT) (Abdolmaleky et al, 2006) and the SOX10 transcription factor gene encoding an important regulator for oligodendrocyte maturation and myelination (Iwamoto et al, 2005), together with corresponding alterations in gene expression, was reported for cerebral cortex from small cohorts of subjects diagnosed with schizophrenia and related disease. These changes, however, did not occur in all postmortem collections explored so far, and when analyses is limited to 
between group differences, disease-associated alterations in epigenetic markings surrounding proximal promoter sequences could show in some cases only subtle changes between cases and controls (Mill et al, 2008; Siegmund et al, 2007; Tochigi et al, 2008). This, of course, is not too surprising. Individual subjects, even those bearing the same psychiatric diagnosis, nonetheless are defined by a considerable degree of heterogeneity - not only in terms of etiology of disease, and underlying genetic risk architecture but also in their various degrees of exposure to alcohol (Marutha Ravindran and Ticku, 2004), nicotine (Satta et al, 2008), psychostimulants (Numachi et al, 2007; Numachi et al, 2004) and many other drugs and environmental factors affecting brain DNA methylation levels. Subjectspecific variabilities in glia-to-neuron ratios due to astrocytic proliferation or microglial invasion (Connor et al, 2011), or loss of oligodendrocyte (Haroutunian et al, 2007) could contribute to additional variability. Therefore, considering that group sizes, particularly in postmortem studies, typically are comparatively small with the $N$ rarely exceeding 100, epigenetic studies solely focused on cohort-based effects of diagnosis are unlikely to bear significant fruit.

However, the above raised skepticisms against cohortbased epigenetic analyses should not distract from the significant merits of that approach. For example, one type of study design, which is presently gaining some traction, is to focus on small regulatory networks involving both epigenetic and/or microRNA-based post-transcriptional modulators of gene expression, as illustrated by several recent postmortem studies conducted on the prefrontal cortex of subjects with schizophrenia and related disease. For example, deficits in a subset of inhibitory neuron-speciifc transcripts could be linked to local levels of neurotrophin supply, particularly brain-derived neurotrophic factor (BDNF), which in turn were modulated by a set of small RNAs including miR-195 (Mellios et al, 2009). In addition, a subset of BDNF gene promoters in schizophrenia prefrontal cortex cannot be fully accessed by the growth arrest and DNA-damage-inducible, beta GADD45b protein, which coordinates DNA demethylation pathways, resulting in excess DNA methylation and hydroxymethylation of BDNF promoter IX and decreased transcription from that site (Gavin et al, 2012). Likewise, dysregulated expression of DNA methyltransferase DNMT3a and various transcription factors was linked to decreased expression of the NMDA-sensitive small RNA, mIR-132 (Miller et al, 2012).

In the following, we discuss how chromatin studies in human brain, in conjunction with genetic approaches, could provide important clues about underlying mechanisms of disease. On the basis of DNA methylation analyses in blood chromatin collected across three generations from the same pedigrees, more than $92 \%$ of the differences in methylcytosine load between alleles is explained by haplotype, suggesting a dominant role of genetic variation in the establishment of epigenetic markings, as opposed to environmental influences (Gertz et al, 2011). Likewise, in the human cerebral and cerebellar cortex, methylation of several hundred $\mathrm{CpG}$ enriched sequences is significantly affected by genetic variations, including single-nucleotide polymorphisms (SNPs) separated from the CpG site by $>1 \mathrm{Mb}$ (Numata et al, 2012; Zhang et al, 2010a). An even larger number of genetic polymorphisms were linked to gene expression differences in the prefrontal cortex, including many SNP-based haplotypes within promoters and around the $5^{\prime}$ ends of annotated transcripts (Colantuoni et al, 2011). Extrapolating from these general findings, it is very likely that genotype is a major driver in the context of epigenetic (dys) regulation and gene expression changes in the diseased brain, with many of the disease-associated mutations and variations likely to be positioned in regulatory and non protein-coding sequences. To speak more clearly, even some of the more optimistic estimates on the role of protein-coding variations, based on recent exome sequencing in subjects with autism and schizophrenia predict that no more than 25 to $50 \%$ of sporadic cases carry disease-associated mutations in protein-coding sequences (O'Roak et al, 2011; Xu et al, 2011).

The following rather simple example, focusing on the GAD1 promoter (chr. 2q31), which regulates GAD67 GABA synthesis enzyme expression, is mentioned here to illustrate the potential merits of exploring disease-relevant genetic and epigenetic risk architectures together in the same subject/tissue. The GAD67 transcript is downregulated in cerebral and cerebellar cortex of a significant portion of subjects diagnosed with schizophrenia, depression or autism and this type of alteration may contribute to desynchronization of cortical networks and cognitive dysfunction because of defective GABAergic inhibition (Akbarian and Huang, 2006; Benes et al, 2007; Blatt and Fatemi, 2011; Curley and Lewis, 2012; Guidotti et al, 2000; Volman et al, 2011). Importantly, both in human and rodent cerebral cortex, Gad1/GAD1 promoter-associated DNA methylation, and multiple histone acetylation and methylation markings are highly regulated during the course of normal development and aging (Huang and Akbarian, 2007a; Huang et al, 2007b; Siegmund et al, 2007; Tang et al, 2011; Zhang et al, 2010b), and are sensitive to exposure of histone deacetylase inhibitor drugs and even to the atypical antipsychotic, clozapine (Chen et al, 2011; Huang et al, 2007b). These findings, taken together, would imply that epigenetic decoration and activity of the Gad1/ GAD1 promoter in the prefrontal cortex is highly sensitive to the impact of multiple non-genetic factors such as drug exposure, disturbed neurodevelopment and so on. Strikingly, however, it is the genetic variants surrounding the $G A D 1$ promoter that recently emerged as a major driver for the disease-related decline in GAD67 transcript and the epigenetic decoration of the proximal GAD1 promoter in subjects with schizoprenia, including the balance between 'open' and 'repressive' histone methylation markings histone $\mathrm{H} 3$ trimethyl-lysines, K4me3 and K27me3 (Huang et al, 2007b). Notably, the same halplotype and polymorphisms, positioned within few $\mathrm{Kb}$ from the GAD1 transcription 
start site, confer genetic risk for accelerated loss of frontal lobe gray matter (Addington et al, 2005; Straub et al, 2007b) and, via epistatic interaction with COMT alleles regulating synaptic dopamine, modulate overall GABA tissue levels in the prefrontal cortex (Marenco et al, 2010). The exact molecular mechanism linking these haplotypes to epigenetic (dys) regulation of GAD1 in diseased tissue remain unclear, but at least a subset of the GAD1 promoter polymorphism implicated in schizophrenia are predicted to alter regulatory sequences and binding motifs for MYOD1 and other types of transcription factors (Straub et al, 2007a). In any case, the $G A D 1$ example reaffirms that genotypic variation is a major driver for the manifestation of epigenetic alterations in diseased brain, with important implications for common psychiatric disorders, such as schizophrenia.

Given the aforementioned examples, and apparent importance of genetic variation (on epigenetic alterations in brains of psychiatric subjects) (Table 1), it is obvious that simple, group-based analysis ('cases' $v s$ 'controls') could often fall short to capture the disease-relevant signal. This problem is further enhanced by the fact that postmortem studies, typically dealing with group sizes far below 100 , are notoriously underpowered. Therefore, we are tempted to predict that in the nearby future, the exploration of epigenetic alterations that are highly specific to individual subjects will, at least on the genome-wide scale (see also Table 1 and Figure 3), emerge as an important alternative to the more conventional, cohort-based approaches in the postmortem field. One possible roadmap for such type of subject-specific approach was recently outlined in a genome-wide study on the transcriptional mark, histone H3-trimethyl-lysine 4 (H3K4me3), conducted on prefrontal cortex of 16 subjects on the autism spectrum. In that study, not one locus reached statistical significance between the case and control cohort. Instead, alterations in specific individuals were essentially defined as statistical outliers via Poisson distribution (Shulha et al, 2011). Using this approach, the study identified more than 700 sequences genome-wide, each ranging in size $0.5-3 \mathrm{~Kb}$, which showed an altered histone methylation profile in at least one of the autism brains, in comparison to each of the controls without exception. By using such type of algorithm, 700 sequences with epigenetic dysregulation in prefrontal cortex of autistic individuals emerged and remarkably, there was a 2-3 fold, significant enrichment for genes and loci conferring genetic risk for neurodevelopmental disease (Shulha et al, 2011). This finding suggest that, at least in autism, epigenetic and genetic risk maps overlap significantly (Shulha et al, 2011). Furthermore, for many loci with an abnormal epigenetic signal in one (or several) autistic individuals, alterations in levels of the corresponding gene transcript could be documented for at least some of the very same cases with altered histone methylation (Shulha et al, 2011). On the basis of these findings, one could conclude that disease-associated molecular pathology was highly specific for each brain, with each individual affected by a unique combinatorial set of abnormal histone methylation levels at select transcription start sites, together with altered expression of the associated gene transcripts. These individual-specific epigenetic alterations in the autism postmortem cohort included AUTS2, PARK2, RIA1, RIMS3, SHANK3, VGEL and many other susceptibility loci with high penetrance for disease risk (Shulha et al, 2011). The next challenge will be to search for potential mutations, or insertions and deletions or some other DNA structural variants, many of which could involve regulatory sequences in cis (at the site of the epigenetic alteration) or perhaps some other portion of the genome. We predict that in the nearby future, an increasing number of postmortem studies will embark in comprehensive epigenome and transcriptome profilings in conjunction with whole-genome sequencing (which is becoming increasingly affordable with a current cost base per genome below $\$ 10000$, including several vendors listed in Table 2). With an ever increasing density of information in the genetic risk databases (at least for a subset of psychiatric conditions, such as autism, schizophrenia and bipolar disorder), such type of analyses could be expected to reveal meaningful information about

TABLE 1 Genome-Wide Surveys Reveal Epigenetic Risk Architectures in Major Psychiatric Disease

\begin{tabular}{|c|c|c|c|c|c|}
\hline Study & Disease & $\mathbf{N}$ & $\begin{array}{l}\text { Brain } \\
\text { region }\end{array}$ & Method & Results \\
\hline $\begin{array}{l}\text { (Mill et al, } \\
\text { 2008) }\end{array}$ & $\begin{array}{l}\text { Schizophrenia, } \\
\text { bipolar } \\
\text { disorder }\end{array}$ & 105 & $\begin{array}{l}\text { Frontal } \\
\text { cortex }\end{array}$ & $\begin{array}{l}\mathrm{mCpG} \text { sensitive restriction digest, } \mathrm{CpG} \text { promoter } \\
\text { array }\end{array}$ & $\begin{array}{l}\text { Approximately } 100 \text { CpG islands with altered DNA methylation in } \\
\text { disease cohorts, BDNF mCpG levels differ between rs6265- } \\
\text { val66met polymorphisms }\end{array}$ \\
\hline $\begin{array}{l}\text { (Xin et al, } \\
2012)\end{array}$ & $\begin{array}{l}\text { Schizophrenia, } \\
\text { depression }\end{array}$ & 29 & $\begin{array}{l}\text { Frontal } \\
\text { cortex }\end{array}$ & $\begin{array}{l}\text { mCpG sensitive restriction digest, paired-end } \\
\text { sequencing }\end{array}$ & $\begin{array}{l}\text { webtool development http://epigenomics.columbia.edu/ } \\
\text { methylomedb/index.html }\end{array}$ \\
\hline $\begin{array}{l}\text { (Shulha et al, } \\
\text { 2011) }\end{array}$ & Autism & 32 & $\begin{array}{l}\text { Frontal } \\
\text { cortex }\end{array}$ & $\begin{array}{l}\text { Neuron-specific histone } \mathrm{H} 3 \mathrm{~K} 4 \mathrm{me} 3 \text { profiling by } \\
\text { fluorescence-activated nuclei sorting (FANS) and } \\
\text { deep sequencing (ChIP-seq) }\end{array}$ & $\begin{array}{l}\text { No significant alteration on group level. Approximately, } 700 \\
\text { sequences with altered H3K4me3 in variable subsets of cases } \\
\text { included } \sim 90 \text { neurodevelopmental risk genes (ASTN2, CACNAIC, } \\
\text { CACNA IH, JMJDIC, MEF2C, NRCAM, PARK2, RAII, RIMS3, RYR2, } \\
\text { SEMA5A, and many others) }\end{array}$ \\
\hline
\end{tabular}


the genetic and epigenetic risk architecture in specific cases and narrow down the potential list of disease-relevant loci in the selected individuals.

\section{A PRIMER ON 'NEXT GENERATION SEQUENCING' AND THE BIOINFORMATICS OF 'ChIP-seq'}

Technological advances have it made possible to profile the distribution of epigenetic marks on a genomic scale using next generation sequencing (NGS) methods. For example, chromatin immunoprecipitation (ChIP) allows enrichment of DNA marked by bound proteins or DNA characterized by modifications of the histone molecules that bind DNA in structural units called nucleosomes (see Figure 1). Initially, genome-wide distribution of epigenetic marks were profiled with microarrays (ChIP-chip) but NGS methods have superseded these demonstrating distinct advantages with increased sensitivity and comprehensiveness of genomic profiles (Park, 2009; Zhao and Grant, 2011). Here, we will therefore concentrate on the ChIP-seq method and will give an overview of the steps involved when analyzing such data.

Several NGS sequencing platforms are in use today for epigenomic research, including Illumina Genome Analyzer, ABI SOLID, Roche 454, Helicos. Typically these platforms produce from hundreds of thousands of reads to hundreds of millions of short sequences called reads or tags with sequence lengths ranging from 35 to $350 \mathrm{bp}$ (depending on the system used). Reads are recovered in the standard fastq format that comprises the read sequence and a quality score for each base call in the tag sequence. Processing and analysis of a ChIP-seq experiment starts with one or more fastq read files.

The first step in the analysis of an ChIP-seq experiment is the mapping of reads to a reference (or known) genome

TABLE 2 Commercial Vendors for Whole-Genome Sequencing Platforms

\begin{tabular}{|c|c|}
\hline Vendor & Web address \\
\hline Knome & http://www.knome.com \\
\hline Complete Genomics & http://www.completegenomics.com \\
\hline Illumina Genome Network & http://www.illumina.com \\
\hline Helicos Biosciences & http://www.helicosbio.com \\
\hline 454 Life Sciences & http://www.454.com \\
\hline Genewiz & http://www.genewiz.com \\
\hline Sequenom & http://www.sequenom.com \\
\hline ION Torrent Systems & http://www.iontorrent.com \\
\hline Halcyon Molecular & http://www.halcyonmolecular.com \\
\hline NABsys & http://www.nabsys.com \\
\hline IBM & http://www.ibm.com \\
\hline GE Biosciences & http://www.gelifesciences.com \\
\hline Bionanomatrix & http://www.bionanogenomics.com \\
\hline Pacific Biosciences & http://www.pacificbiosciences.com \\
\hline Applied Biosystems & http://www.appliedbiosystems.com \\
\hline
\end{tabular}

followed by (i) conversion of the mapped reads into integer counts of reads at each position of the genome (coverage), (ii) selection of enriched genomic regions (peak calling), and (iii) evaluating the significance of called peaks (significance ranking), and (iv) visualization. We will briefly outline each analysis step and point to bioinformatics software helpful to carry out these steps.

The mapping step refers to finding the location of the large numbers of short DNA sequences on a known reference genome and is accomplished by sequence alignment. Traditional sequence alignment methods (Blast (Altschul et al, 1990), Blat (Kent, 2002), Smith-Waterman (Smith and Waterman, 1981)) do not scale well to the small size and large numbers of sequenced fragments produced by the new sequencers. Useful alignment tools should be able to perform the many alignments in a reasonable amount of time and without too big a memory footprint. As a result new computational algorithms have been and are still developed to fulfill these efficiency and memory requirements and multiple open source and commercial implementations are available to groups involved in epigenomic research. The bowtie software (Langmead et al, 2009) is a commonly used implementation of the 'seed and extend' approach for fast sequence alignment and achieves an acceptable balance between speed and memory usage. Most of these alignment programs are commandline tools tunable by setting many parameters affecting the specificity and selectivity of the analysis results. A reasonable approach is to start with the default parameters and systematically vary the parameter values until an acceptable number of reads are aligned. Read alignment algorithms are an active field of bioinformatics research and are reviewed in (Flicek and Birney, 2009) The SeqAnswers wiki site (http:// seqanswers.com/wiki/Special:BrowseData) provides updated listings of read alignment software and peak finder programs essential for carrying out additional portions of the ChIP-seq data analysis, including those outlined in the next paragraph (Pepke et al, 2009).

Once the sequence reads are mapped a read distribution is established on the genome for each sample where each position on the genome is supplied with the number of reads mapping on that position. The essential ChIP-seq analysis step then is to find regions of the genome where the integer distribution function of the ChIP sample has a larger value than a control distribution. The control distribution can be empirical or theoretical. Empirically it is based on mapped genomic reads or ChIP-seq reads where the immunoprecipitation is performed with a non-specific antibody. A theoretical distribution is based on the Poisson distribution or negative binomial distribution. Epigenomics analysts can choose from a plethora of open source software tools to perform the peak finder step. Earlier tools were optimized to find transciption factor binding events. These tend to find puncate regions typical for such events. In contrast, some types of histone modifications cover broader regions, which earlier software would miss. To date, a validated, complete epigenomic data set does not exist 
against which a software tool can be tested. However, several unbiased validation sets are available and it is advisable to choose a tool ranked high in a performance comparison with such data sets (Micsinai et al, 2012).

\section{CHALLENGES FOR EPIGENETIC APPROACHES IN (HUMAN) BRAIN}

\section{Cellular Specificity of Epigenetic Markings}

Conventional chromatin assays designed to detect and quantify DNA methylation and histone modifications require an input material between $10^{3}-10^{8}$ nuclei (Adli and Bernstein, 2011; Huang et al, 2006). Such types of assay typically lack cellular resolution, which poses a challenge given that brain tissue is comprised of an extremely heterogeneous mixture of different cell types, including glia-to-neuron ratios that could show considerable fluctuations in developmental or certain disease states. To date, many studies exploring epigenetic dysregulation of gene expression in major psychiatric disease examined DNA methylation and histone modifications in tissue homogenates, thus ignoring the fact that the gene(s)-of-interest often are expressed only in a select subpopulation of neurons or other cells (Abdolmaleky et al, 2006; Abdolmaleky et al, 2005; Grayson et al, 2005; Huang et al, 2007b; Iwamoto et al, 2005; Mill et al, 2008; Siegmund et al, 2007; Tamura et al, 2007; Tochigi et al, 2008). This is not a trivial point, given that multipe reports emphasized the differential regulation of DNA and histone methylation at hundreds or thousands of promoter and enhancer sequences depending on cell type, resulting in considerable 'epigenetic distance' even between cortical neurons and their surrounding glia and other non-neuronal cells (Cheung et al, 2010; Iwamoto et al, 2011; Sugawara et al, 2011). Additional differences may exist between chromatin of specific neuronal subtypes. For example, some of reported changes, such as the hypermethylation of the REELIN promoter DNA in cortical layer I of subjects with schizophrenia (Grayson et al, 2005; Veldic et al, 2004; Veldic et al, 2005), or the aforementioned shift from open chromatin-associated (H3-trimethyl-K4) to repressive histone methylation (H3-trimethylK27) at the GAD1 gene promoter could indicate an epigenetic defect in the population of inhibitory interneurons in psychosis (Huang et al, 2007b). This is a very attractive working hypothesis that could potentially explain the observed deficits in the corresponding REELIN and GAD1 (GAD67) RNAs (Guidotti et al, 2009). However, a more conclusive test of this hypothesis has to await the development of technologies for efficient sorting of GABAergic neuron chromatin directly from postmortem tissue. In principle, this is not an unsurmountable task. Methods have been developed to purify and immunotag (with anti-neuronal nucleus, NeuN antibody) neuronal nuclei, for efficient fluorescence-activated sorting and separation of $10^{7}-10^{8}$ neuronal and non-neuronal nuclei from less than $1 \mathrm{~g}$ of postmortem cerebral cortex in a single day, thereby enabling separate processing of neuronal and non-neuronal chromatin (Jiang et al, 2008; Matevossian and Akbarian, 2008) (Figure 2). These approaches should be, in principle, also applicable to capture selected interneuron subtypes or other neuronal subpopulations. Related approaches were recently employed to sort-specific subtypes of non-neuronal cells, including oligodendroglia (Hayashi et al, 2011). One important limitation of the nuclei sorting approach is the need for epitopes that are selectively expressed in the nucleus of the cell type-of-interest, and sufficiently stable to maintain robust immunoreactivity during tissue autolysis. In an alternative approach, chromatin fragments (not nuclei) are sorted from tissue homogenates with a set of anti-methylDNA or modification-specific anti-histone antibodies that differentiate between open chromatin at sites of actual or potential gene expression, as opposed to repressive chromatin. After this first round of chromatin pulldown, additional epigenetic markings could then be measured separately in the open $v s$ repressive chromatin fractions. For example, when chromatin from postmortem cerebral cortex homogenates is fractionated by pulldown for selective enrichment of trimethylated histone H3K27me3 (a repressive mark) and aforementioned open chromatin-associated $\mathrm{H} 3 \mathrm{~K} 4 \mathrm{me} 3$, and then assayed for methyl-CpG densities, the GAD1 locus showed much higher DNA methylation levels in the repressive (H3K27me3) fraction, compared with open chromatin (H3K4me3) (Huang and Akbarian, 2007a). Additional case-control studies then revealed GAD1-associated DNA methylation deficits selectively in the repressive chromatin fraction from the prefrontal cortex of schizophrenia subjects (Huang and Akbarian, 2007a). The above examples, taken together, clearly demonstrate the potential merits of separating various chromatin fractions, defined by cell type and/or functional status, from brain homogenates before quantitative analyses of a specific epigenetic marking. Once approaches such as cell type-specific epigenome mappings will become more established in clinical and translational brain research, it will be exciting to explore chromatin structure and function of cell types ascribed a key role in a wide range of neuropsychiatric conditions, such as midbrain dopaminergic neurons, medium spiny neurons in the ventral striatum, prefrontal and hippocampal interneurons and so on.

\section{Epigenetic Markings In Brain — State Or Trait?}

The rationale to explore certain types of epigenetic modifications in postmortem brain of subjects diagnosed with psychiatric disease is, as mentioned above, often based on the hypotheses that changes in RNA expression are associated with altered epigenetic decoration at the site of the corresponding gene promoter and related regulatory sequences. Quite often the accompanying abnormalities in DNA methylation and histone modifications are then interpretated in terms of a stable and long-lasting epigenetic 'lesion' in response to an environmental insult or some other pathogenic effect operating in early life, many years before the brain was obtained at autopsy. For example, 

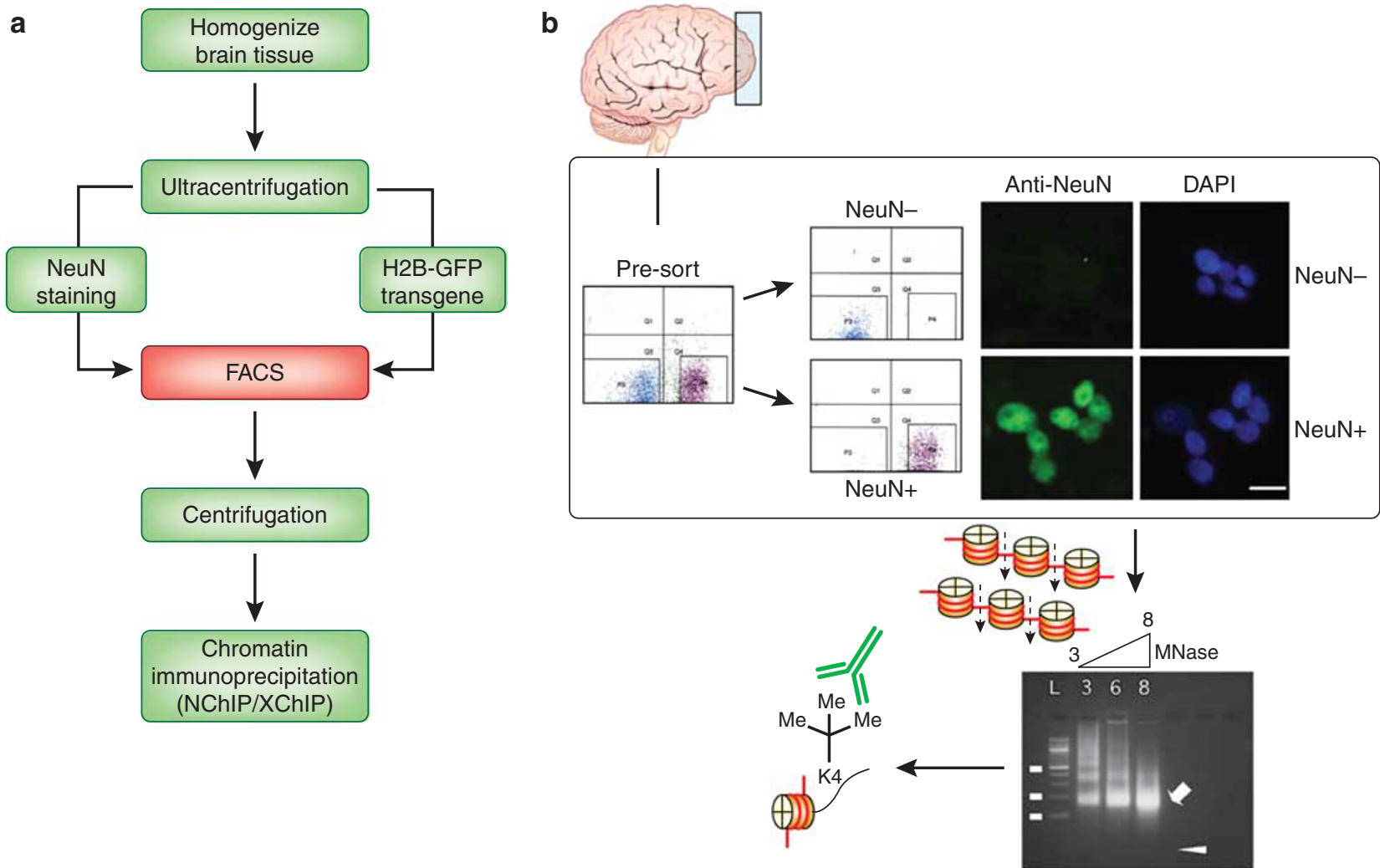

Figure 2. Flow diagram of nuclei sorting procedure, including fluorescence-activated separation and sorting of NeuN + and NeuN- nuclei from brain tissue. For analyses of histone modifications, sorted nuclei are subjected to micrococcal nuclease-based enzymatic digestion of chromatin into mononucleosomes ( 146 bp long) for subsequent immunoprecipitation with modification-specific histone antibody.

different grades of maternal care in the early postnatal period lead to differential regulation of promoter-associated DNA methylation and histone acetylation at the aforementioned disease gene, Gad1, in hippocampus of adult rats (Zhang et al, 2010b), and likewise, deficits in open chromatin-associated histone methylation at GAD1 in prefrontal cortex of adult schizophrenics was discussed in the context of defective neurodevelopment in conjunction with a risk haplotype at the promoter (Huang et al, 2007b). Furthermore, based on postmortem studies in adult suicide victims, there is evidence that the suffering of abuse in early childhood years leaves a lasting DNA methylation imprint on the stress regulated glucocorticoid receptor NR3C1 promoter (McGowan et al, 2009) in the hippocampus, and on DNA repeats encoding ribosomal RNAs (McGowan et al, 2008).

However, it is fair to admit that little is known about the stability and dynamic turnover of epigenetic markings in human brain and therefore it remains unclear whether any of the aforementioned epigenetic alterations in the brain of adult psychiatric subjects indeed reflect a (mal) adaptive 'trait' stably maintained for years, or alternatively, whether disease-associated chromatin changes merely reflect the brain's functional state at the time of death. The 'trait' hypothesis appears very plausible in the context of monogenetic disorders associated with aberrant and excessive repressive DNA and histone methylation in cis (at the site of the mutation). Examples include the aforementioned $C G G$ triplet expansion at the FMR1 (fragile $\mathrm{X}$ ) gene promoter (Oberle et al, 1991), or the GAA triplet repeat expansion in the first intron of the FRATAXIN gene associated with Friedreich ataxia, an autosomal recessive neurodegenerative condition (Al-Mahdawi et al, 2008). In these cases, the epigenetic dysregulation is firmly linked to the pathophysiology of disease (resulting from silenced gene expression), and there can be little doubt that the observed changes in (postmortem) brain chromatin, like the impairments in neurological functions, most likely existed across the entire lifespan (Al-Mahdawi et al, 2008; Tassone et al, 1999). Furthermore, there are many other examples strongly suggesting that the DNA sequence variation is a major driver for epigenetic differences between subjects. In addition to the above mentioned example gene, GAD1, many other single-SNPs across the entire genome, including those that have been genetically implicated in the risk of major psychiatric disease (including bipolar disorder and schizophrenia), exhibit a robust effect on methyl cytosine levels at the site of nearby genes (Gamazon et al, 2012; Numata et al, 2012). However, studies in mono and dizygotic twins and related work in animals convincingly demonstrated that molecular mechanisms of heritability are unlikely due to DNA sequence differences alone (Kaminsky et al, 2009).

On the other hand, it will be difficult to confirm whether many of the reported epigenetic alterations observed in 
small cohorts of 'sporadic' cases with schizophrenia, autism, depression and other psychiatric disease, represent a type of molecular alteration stably related to the underlying disease. Given that most, or perhaps all epigenetic markings studied to date are subject to bidirectional regulation in the cell culture system and animal model, it is reasonable to assume that the epigenetic decoration of human brain genomes is subject to similar types of dynamic regulation. For example, DNA methylation at specific promoter sequences is subject to rapid up or downregulation on the scale of minutes to hours (Kundakovic et al, 2007; Levenson et al, 2006). Hippocampal DNA methylation signatures are highly sensitive to acute depolarization (Martinowich et al, 2003; Nelson et al, 2008) and electroconvulsive seizures, affecting regulatory sequences regulating $N M D A$ and $G A B A-A$ receptor genes, Notch-signaling pathways and other systems with a key regulatory role for synaptic signal and plasticity (Guo et al, 2011).

Furthermore, changes in neuronal activity result in robust changes in expression and activity of multiple DNA methylation-associated proteins with an essential role for neuronal health and function, including the methyl-CpGbinding protein $\mathrm{MeCP} 2$ or Gadd45b, which recruits cytidine deaminases and thymidine glycosylases at genomic sites subject to active DNA methylation (Cohen et al, 2011; Li et al, 2011b; Ma et al, 2009). Furthermore, based on work done in rodents, even physiological activation of hippocampal circuitry during learning and memory is sufficient to elicit highly dynamic DNA methylation changes at PP1, REELIN and other gene promoters regulating synaptic plasticity (Day and Sweatt, 2010; Miller et al, 2010). The complex molecular machineries mediating demethylation of $\mathrm{CpG}$ dinucleotides or histone lysine residues are becoming increasingly understood, which is remarkable progress given that these and other types of epigenetic modifications were not long ago considered to be potentially irreversible (Klose and Zhang, 2007; Loenarz and Schofield, 2011; Miller and Sweatt, 2007; Ooi and Bestor, 2008). Given the above, one cannot exclude that at least some of the epigenetic alterations reported in diseased postmortem brain are not necessarily stable imprints that exist for very long periods of time, and instead, could potentially reflect a mechanism that operated on a much shorter time scale before death, perhaps lasting only a few days or even less. The rapidly growling list of conditions acutely affecting the regulation of chromatin structure and function in brain includes ischemia (Endres et al, 2000), and exposure to environmental toxins (Bollati et al, 2007; Desaulniers et al, 2005; Salnikow and Zhitkovich, 2008), nicotine (Satta et al, 2008), alcohol (Marutha Ravindran and Ticku, 2004), psychostimulants (LaPlant et al, 2010; Numachi et al, 2007; Numachi et al, 2004), antipsychotic drugs (Cheng et al, 2008; Dong et al, 2008; Li et al, 2004; Mill et al, 2008; Shimabukuro et al, 2006) and mood stabilizers such as lithium (Kwon and Houpt, 2010) and valproate (Bredy et al, 2007; Dong et al, 2008).

\section{PSYCHIATRIC EPIGENETICS IN THE CULTURE DISH?}

Given the aforementioned confounds and caveats inherent to any work on postmortem brain tissue, it is not surprising that many investigators in the field are beginning to embark on projects involving induced pluripotent stem cells (iPS), using skin grafts or other cell types provided by patients and controls as the starting material. During the last 6 years following the initial report of successful generation of pluripotent stem cells by reprogramming somatic cells via retroviral transduction of four transcription factors (ie, Oct4, Sox2, Klf4, and c-Myc) (Takahashi and Yamanaka, 2006), the technique has been further advanced (Kim, 2010) and applied by multiple groups to generate iPS-derived neuronal and glial cultures from patients (and animal models) to study brain disease in the culture dish. Examples include amyotrophic lateral sclerosis (motor neuron disease) (Dimos et al, 2008), Parkinson's disease (Wernig et al, 2008), Rett syndrome (Farra et al, 2012; Muotri et al, 2010), and schizophrenia (Brennand et al, 2011). These pioneering studies have paved the way for future iPS-based approaches that most certainly will become a mainstay in the field of biological psychiatry. Cellular reprogramming with subsequent neural differentiation, including neural circuitry and active synapse formation in the dish, is likely to mimic many key steps of neurodevelopment, and opens up the possibility to conduct electrophysiological recordings and other functional assays on nervous tissues of living subjects (Brennand et al, 2011). Therefore, iPS technology provides an unprecedented opportunity to study the molecular and cellular biology of the nervous system from any patient (or at least from those who are able to give consent). Notably, many established psychiatric susceptibility genes, such as NEUREGULIN1 (NRG1), NEUREXIN1 (NRXN1) and many others show dynamic changes in expression during the course of neural differentiation of reprogrammed skin cells (Lin et al, 2011). A subset of psychiatric susceptibility genes may even, as in case of the MYLT1 transcription factor, which when mutated confers high risk for neurodevelopmental disability, promote the process of neuronal differentiation from stem cell preparations ex vivo (Pang et al, 2011; Stevens et al, 2011).

These recent advances in reprogramming technologies have also fueled general interest in the field to explore epigenetic regulation of the nervous system in patient- and control-derived iPS. For example, several studies explored chromatin structures and synaptic signaling in neuronal cultures of Rett syndrome patients with MECP2 mutations and controls (Farra et al, 2012; Muotri et al, 2010). The $M E C P 2$ gene product, methyl-CpG-binding protein 2, is highly expressed in the nervous system and occupies widespread territories of neuronal chromatin, dependent on the local density of methyl-CpG-dinucleotides (Skene et al, 2010). Loss-of-function mutations and other MECP2 structural variants have been linked to Rett syndrome, a disorder of early childhood associated with developmental 
and cognitive regression and a broad range of neurological symptoms (Amir et al, 1999; Chouery et al, 2011). The molecular and cellular mechanisms linking MECP2 mutations to neuronal dysfunction and brain disease remain incompletely understood. Importantly, work on reprogrammed skin cells of Rett patients and Mecp2 mutant mouse brain associates loss of $\mathrm{MeCP} 2$ function with disinhibition and increased genomic mobility of retrotransposon and other parasitic DNA element activities because of altered DNA and histone methylation, in conjunction with changes in the global chromatin state (Muotri et al, 2010; Skene et al, 2010). This work illustrates the promising potential of neural cultures, derived from skin fibroblasts, to study epigenetic (dys) regulation in specific disease cases and to gain knowledge about the molecular underpinnings of neurological disorders.

Interestingly, the short chain fatty acid derivative valproic acid (VPA), a widely prescribed mood stabilizer and anticonvulsant drug acting as a broad histone deacetylase inhibitor induces pluripotency from skin fibroblasts when co-administered with Oct-4 and Sox-2 transcription factors (Huangfu et al, 2008). Furthermore, VPA promotes neuronal differentiation from progenitor stages (Hsieh et al, 2004; Yu et al, 2009) and the drug induces in cell culture and brain the upregulation of open chromatinassociated histone acetylation and methylation markings at promoters of genes with a key role in neurotransmission (Gavin et al, 2009; Guidotti et al, 2009; Huang et al, 2007b). It will be interesting to quantify these VPA-dependent effects on pluripotency and neuronal differentiation, and to compare VPA treatment responders to non-responders. More broadly, pharmacoepigenomics, or a drug's direct and indirect effects on chromatin structure and function, may perhaps in the future emerge as an interesting biomarker to predict treatment response, side effects or illuminate novel, hitherto unsuspected mechanisms of drug action. While this prediction is presently highly speculative, it is interesting to note that a wide range of psychoactive drugs, including dopamine receptor agonists (Schroeder et al, 2008), typical and atypical antipsychotics (Huang et al, 2007b; Li et al, 2004), and several mood-stabilizers, including lithium and valproate (Bredy et al, 2007; Dong et al, 2008; Kwon and Houpt, 2010), were shown to affect DNA methylation and/or histone acetylation, phosphorylation, and methylation in selected areas of the forebrain.

However, despite of all these unprecedented perspectives of generating nervous tissue in the dish from skin cells, it is important to point out that the technique still faces hurdles and challenges, particularly in the context of epigenetic regulation. This is because the eraser and subsequent redecoration of epigenetic markings across the genome- $a$ key mechanism for successful reprogramming-may be incomplete at some loci, resulting in carry over effects so that the reprogrammed cells (iPS) maintain DNA methylation signatures, which define the original donor cell type (eg, fibroblasts) (Nishino et al, 2011; Ohi et al, 2011). Similarly, the exact choice of transcription factors used to induce reprogramming, including relative levels of $O c t-4, c$ $m y c$ and Sox-2 result in robust differences of the resulting iPS cells, including their pluripotency and oncogenic potential (Carey et al, 2011). Therefore, there is considerable variability of cellular phenotypes after reprogramming, and it will be difficult to faithfully 'rebuild' in the culture dish the cortical neuronal networks with their constituents such as pyramidal neurons and their surrounding inhibitory cells. This is a challenge for any disease-related study, including many psychiatric disorders, which are likely to show only subtle differences in cellular response patterns, as compared with controls. Based on the above, it appears important to minimize these variabilities to avoid falsepositive conclusions. Among the list of reasonable countermeasures would be generation of multiple reprogrammed lines collected from the same subject, or careful choice of transfection conditions in order to minimize interindiviudal dfferences in treatment.

While purely speculative at this point in time, imagine the potential benefits of the iPS technology for pharmaco(epi)genomics and treatment response paradigm. For example, iPS-derived cells could be 'challenged' with a compound and the epigenome signature measured to distinguish between treatment-resistant and treatment-responsive patients. In this context, one interesting biomarker appears to be related to levels histone methylation and acetylation levels in peripheral blood cells of subjects exposed to the histone deacetylase inhibitor, valproate (Gavin et al, 2008).

\section{EPIGENOME ORGANIZATION AND HIGHER ORDER CHROMATIN STRUCTURES}

Although nucleosomal organization leads to a sevenfold increase in packaging density of the genetic material, as compared with naked DNA, the actual level of compaction in the vertebrate nucleus is about three orders of magnitude higher (Belmont, 2006). These chromosomal arrangements in the interphase nucleus are not random. For example, loci with active transcription are more likely to be clustered together and positioned towards a central position within the nucleus, whereas heterochromatin and silenced loci tend to locate towards the nuclear periphery (Cremer and Cremer, 2001; Duan et al, 2010). Chromatin loopings, in particular, are among the most highly regulated 'supranucleosomal' structures and pivotal for the orderly process of gene expression, by enabling distal regulatory enhancer or silencer elements positioned a few, or many hundred kilobases apart from a gene, to interact directly with that specific promoter (Gaszner and Felsenfeld, 2006; Wood et al, 2010). Despite of the growing realization of the importance of these and other higher order chromatin structures for transcriptional regulation, very little is known about their role in the nervous system. Until recently, there were only three studies in the literature that explored loop formations in brain tissue (Dhar et al, 2009; Horike et al, 2005; Jiang et al, 2010), with a few additional papers using 
the brain as negative control for their studies on the sensory epithelium of the nose (Lomvardas et al, 2006) or the hematopoetic system (Simonis et al, 2006). However, to date, nothing is known about chromatin loopings in human brain. The assays for mapping of three-dimensional architectures are also known as 3C (chromosome conformation capture) assays. The $3 \mathrm{C}$ technique explores physical interactions between DNA fragments separated by $\mathrm{Kb}$ or $\mathrm{Mb}$ of interspersed sequence; crosslinked chromatin is digested with a specific restriction enzyme, religated and amplified using primer pairs for which forward and reverse primers match to different portions of the genomic locus-of-interest. It will be important to clarify in the nearby future whether the $3 \mathrm{C}$ technique (and some of its higher order or even genome-scale derivatives, such as 4C, 5C or HiC (Simonis et al, 2007)) is compatible with postmortem brain tissue. If this turns out to be the case, then the exploration of these higher order chromatin structures will provide an important and new level of information, as it pertains to genome organization and chromosomal configurations and architecture in CNS interphase nuclei. Specifically, successful implementation of the technique in postmortem brain would open up the opportunity to map at the site of disease risk genes the promoter-enhancer interactions and to uncover novel regulatory sequences hitherto not 'visible', because often they are in a linear genome spatially separated form transcription start sites by hundreds of kilobases. To highlight the potential use of chromosome conformation capture in the context of psychiatric disease, consider the example of the major histocompatibility complex (MHC) locus, which long has been implicated in psychiatric disease, conferring significant genetic risk to schizophrenia and related disease as most recently shown in three large GWAS studies published jointly in 2009 (Purcell et al, 2009; Shi et al, 2009; Stefansson et al, 2009). These studies identified up to 45 disease-associated SNPs in the 26-33-Mb region of the MHC loci on chromosome 6. Strikingly, 50\% of these SNPS are not located near genes and in fact, the strongest SNP at rs13194053 $\left(P=9.54 \times 10^{-9}\right)$ is more than $29 \mathrm{~kb}$ away from its nearest gene HIST1H2AH. A functional role for many intergenic regions would not be surprising as many intergenic regions alter expression of upstream and downstream genes (Kleinjan and van Heyningen, 2005), and the mechanistic work-up of these SNPs will certainly require application of chromosome conformation capture and related technologies.

\section{SYNOPSIS AND OUTLOOK}

Over the course of only a few years, we have witnessed a proliferation of epigenetic studies in human brain, ranging from exploration of chromatin structures at a specific genomic locus to genome-wide epigenome mapping in defined cell types, generally with signal-to-noise ratios and signal quality comparable to those obtained in animal brains. Work from multiple groups, focusing mainly on human association cortex, point to large-scale remodeling of DNA and histone methylation landscapes during the late pre- and early postnatal phase and early childhood, with comparatively less dramatic changes during subsequent stages of development and aging (Cheung et al, 2010; Numata et al, 2012). Still, hundreds of promoters are subject to epigenetic changes that seemingly continue into old age, and these data, taken together, leave little doubt that chromatin structures undergo remodeling throughout the lifespan of the human brain (Hernandez et al, 2011; Numata et al, 2012; Siegmund et al, 2007), including neurons and other terminally differentiated cells (Cheung et al, 2010). Based on postmortem brain work, epigenetic risk architectures are beginning to emerge for a number of common psychiatric conditions and disorders, including autism (Shulha et al, 2011), schizophrenia (Akbarian, 2010), depression and bipolar disorder (Gamazon et al, 2012; Tang et al, 2011) and alcoholism (Taqi et al, 2011) (see also

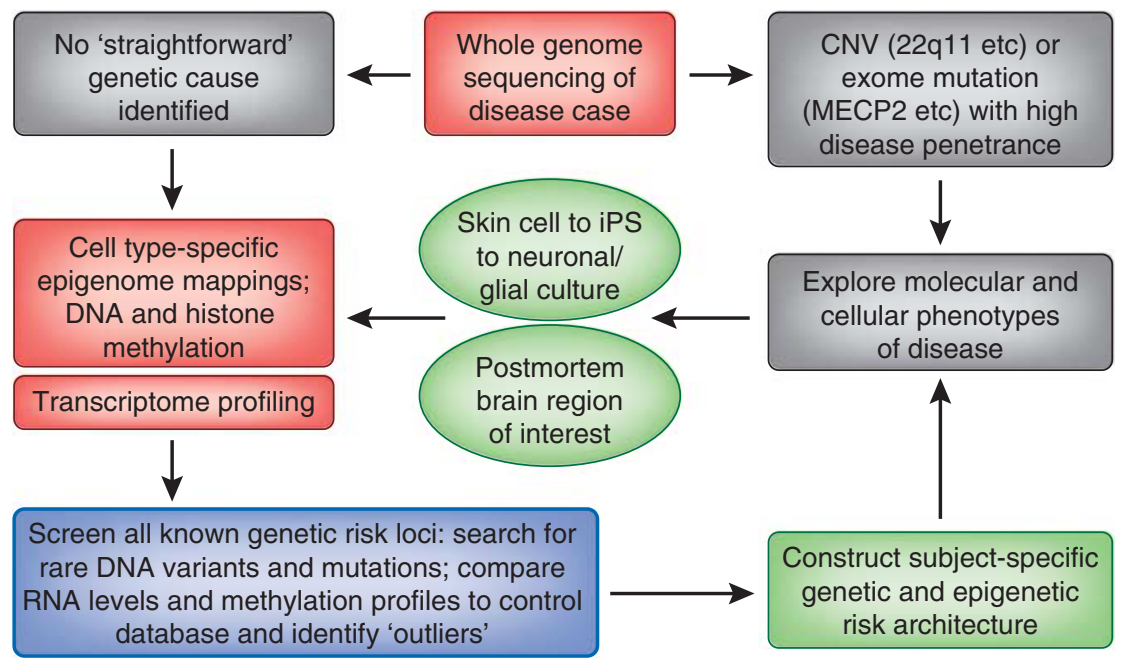

Figure 3. Flow chart aimed at defining subject-specific genetic and epigenetic risk architectures of psychiatric disease. See text for additional details. 
Table 1). We predict that only very few, if any, loci will show group-based differences when assayed in genome-wide epigenetic screens. Instead, we argue that epigenetic exploration of brain cells and tissue is ideally done in phenotypically well-characterized subjects, in conjunction with whole genome and transcriptome sequencing of the same cases and tissues. A principle roadmap, or 'flowchart' for a proper work-up of so-called 'sporadic' disease cases is presented in Figure 3. Such type of comprehensive approach could be expected to uncover, in a substantial portion of cases, disease-relevant mutations in regulatory and other sequences that are not well captured by conventional exome-sequencing platforms. Of note, only $1-1.5 \%$ of the genome encodes protein-coding sequences, therefore exome sequencing will exclude a large majority of the genome from analyses. The important role of epigenetically regulated non-coding DNA was further ascertained in by recent bioinformatical analyses, by showing that these regions are generally deficient of SNP and underwent a purifying selection (Tolstorukov et al, 2011). Without question, the epigenetic exploration of the human brain, including high resolution mapping of DNA and histone modifications and histone variant distribution, as well as charting of higher order chromatin structures, will continue to be a most exciting endeavor to gain critical insights into the mechanisms of normal and diseased human development and aging.

\section{ACKNOWLEDGEMENTS}

Work conducted in the authors laboratories is sponsored by the National Institutes of Health, including R01MH093332, R01MH081943, R01086509 (SA), DARPA (SA), Autism Speaks (SA) and the Rostock Group and R01 AG029360 (ER).

\section{DISCLOSURE}

The authors declare no conflict of interest.

\section{REFERENCES}

Abdolmaleky HM, Cheng KH, Faraone SV, Wilcox M, Glatt SJ, Gao F et al (2006). Hypomethylation of MB-COMT promoter is a major risk factor for schizophrenia and bipolar disorder. Hum Mol Genet 15: 3132-3145.

Abdolmaleky HM, Cheng KH, Russo A, Smith CL, Faraone SV, Wilcox M et al (2005). Hypermethylation of the reelin (RELN) promoter in the brain of schizophrenic patients: a preliminary report. Am J Med Genet B Neuropsychiatr Genet 134B: 60-66.

Addington AM, Gornick M, Duckworth J, Sporn A, Gogtay N, Bobb A et al (2005). GAD1 (2q31.1), which encodes glutamic acid decarboxylase (GAD67), is associated with childhood-onset schizophrenia and cortical gray matter volume loss. Mol Psychiatry 10: 581-588.

Adli M, Bernstein BE (2011). Whole-genome chromatin profiling from limited numbers of cells using nano-ChIP-seq. Nat Protoc 6: 1656-1668.

Akbarian S (2010). Epigenetics of schizophrenia. Curr Top Behav Neurosci 4: $611-628$.

Akbarian S, Huang HS (2006). Molecular and cellular mechanisms of altered GAD1/ GAD67 expression in schizophrenia and related disorders. Brain Res Rev 52: 293-304.

Al-Mahdawi S, Pinto RM, Ismail O, Varshney D, Lymperi S, Sandi C et al (2008). The Friedreich ataxia GAA repeat expansion mutation induces comparable epigenetic changes in human and transgenic mouse brain and heart tissues. Hum $\mathrm{Mol}$ Genet 17: 735-746.

Altschul SF, Gish W, Miller W, Myers EW, Lipman DJ (1990). Basic local alignment search tool. J Mol Biol 215: 403-410.

Amir RE, Van den Veyver IB, Wan M, Tran CQ, Francke U, Zoghbi HY (1999). Rett syndrome is caused by mutations in X-linked MECP2, encoding methyl-CpGbinding protein 2. Nat Genet 23: 185-188.

Belmont AS (2006). Mitotic chromosome structure and condensation. Curr Opin Cell Biol 18: 632-638.

Benes FM, Lim B, Matzilevich D, Walsh JP, Subburaju S, Minns M (2007). Regulation of the GABA cell phenotype in hippocampus of schizophrenics and bipolars. Proc Natl Acad Sci USA 104: 10164-10169.

Bintu L, Kopaczynska M, Hodges C, Lubkowska L, Kashlev M, Bustamante C (2011). The elongation rate of RNA polymerase determines the fate of transcribed nucleosomes. Nat Struct Mol Biol 18: 1394-1399.

Blatt GJ, Fatemi SH (2011). Alterations in GABAergic biomarkers in the autism brain: research findings and clinical implications. Anat Rec 294: 1646-1652.

Bollati V, Baccarelli A, Hou L, Bonzini M, Fustinoni S, Cavallo D et al (2007). Changes in DNA methylation patterns in subjects exposed to low-dose benzene. Cancer Res 67: 876-880.

Bredy TW, Wu H, Crego C, Zellhoefer J, Sun YE, Barad M (2007). Histone modifications around individual BDNF gene promoters in prefrontal cortex are associated with extinction of conditioned fear. Learn Mem 14: 268-276.

Brennand KJ, Simone A, Jou J, Gelboin-Burkhart C, Tran N, Sangar S et al (2011). Modelling schizophrenia using human induced pluripotent stem cells. Nature 473: 221-225.

Carey BW, Markoulaki S, Hanna JH, Faddah DA, Buganim Y, Kim J et al (2011). Reprogramming factor stoichiometry influences the epigenetic state and biological properties of induced pluripotent stem cells. Cell Stem Cell 9: 588-598.

Chen Y, Dong E, Grayson DR (2011). Analysis of the GAD1 promoter: trans-acting factors and DNA methylation converge on the $5^{\prime}$ untranslated region. Neuropharmacology 60: 1075-1087.

Cheng MC, Liao DL, Hsiung CA, Chen CY, Liao YC, Chen CH (2008). Chronic treatment with aripiprazole induces differential gene expression in the rat frontal cortex. Int J Neuropsychopharmacol 11: 207-216.

Cheung I, Shulha HP, Jiang Y, Matevossian A, Wang J, Weng Z et al (2010). Developmental regulation and individual differences of neuronal H3K4me3 epigenomes in the prefrontal cortex. Proc Natl Acad Sci USA 107: 8824-8829.

Chouery E, Ghoch JA, Corbani S, Ali NE, Korban R, Salem N et al (2011). A novel deletion in ZBTB24 in a Lebanese family with Immunodeficiency, Centromeric Instability, and Facial Anomalies Syndrome Type 2. Clin Genet; e-pub ahead of print 9 September 2011.

Cohen S, Gabel HW, Hemberg M, Hutchinson AN, Sadacca LA, Ebert DH et al (2011). Genome-wide activity-dependent MeCP2 phosphorylation regulates nervous system development and function. Neuron 72: 72-85.

Colantuoni C, Lipska BK, Ye T, Hyde TM, Tao R, Leek JT et al (2011). Temporal dynamics and genetic control of transcription in the human prefrontal cortex. Nature 478: 519-523.

Connor CM, Crawford BC, Akbarian S (2011). White matter neuron alterations in schizophrenia and related disorders. Int J Dev Neurosci 29: 325-334.

Cremer T, Cremer C (2001). Chromosome territories, nuclear architecture and gene regulation in mammalian cells. Nat Rev Genet 2: 292-301.

Curley AA, Lewis DA (2012). Cortical basket cell dysfunction in schizophrenia. $J$ Physiol 590(Part 4): 715-724.

Day JJ, Sweatt JD (2010). DNA methylation and memory formation. Nat Neurosci 13: $1319-1323$

Desaulniers D, Xiao GH, Leingartner K, Chu I, Musicki B, Tsang BK (2005). Comparisons of brain, uterus, and liver mRNA expression for cytochrome p450 s, DNA methyltransferase-1, and catechol-o-methyltransferase in prepubertal female Sprague-Dawley rats exposed to a mixture of aryl hydrocarbon receptor agonists. Toxicol Sci 86: 175-184.

Dhar SS, Ongwijitwat S, Wong-Riley MT (2009). Chromosome conformation capture of all 13 genomic Loci in the transcriptional regulation of the multisubunit bigenomic cytochrome C oxidase in neurons. J Biol Chem 284: 18644-18650.

Dimos JT, Rodolfa KT, Niakan KK, Weisenthal LM, Mitsumoto H, Chung W et al (2008). Induced pluripotent stem cells generated from patients with ALS can be differentiated into motor neurons. Science 321: 1218-1221.

Dong E, Nelson M, Grayson DR, Costa E, Guidotti A (2008). Clozapine and sulpiride but not haloperidol or olanzapine activate brain DNA demethylation. Proc Natl Acad Sci USA 105: 13614-13619.

Duan Z, Andronescu M, Schutz K, Mcllwain S, Kim YJ, Lee C et al (2010). A threedimensional model of the yeast genome. Nature 465: 363-367. 
Ederveen TH, Mandemaker IK, Logie C (2011). The human histone H3 complement anno 2011. Biochem Biophys Acta 1809: 577-586.

Endres M, Meisel A, Biniszkiewicz D, Namura S, Prass K, Ruscher K et al (2000). DNA methyltransferase contributes to delayed ischemic brain injury. J Neurosci 20: 3175-3181.

Ernst C, McGowan PO, Deleva V, Meaney MJ, Szyf M, Turecki G (2008). The effects of $\mathrm{pH}$ on DNA methylation state: In vitro and post-mortem brain studies. J Neurosci Methods 174: 123-125.

Farra N, Zhang WB, Pasceri P, Eubanks JH, Salter MW, Ellis J (2012). Rett syndrome induced pluripotent stem cell-derived neurons reveal novel neurophysiological alterations. Mol Psychiatry. 2012; e-pub ahead of print 10 January 2012.

Flicek P, Birney E (2009). Sense from sequence reads: methods for alignment and assembly. Nat Methods 6(11 Suppl): S6-S12.

Gamazon ER, Badner JA, Cheng L, Zhang C, Zhang D, Cox NJ et al (2012). Enrichment of cis-regulatory gene expression SNPs and methylation quantitative trait loci among bipolar disorder susceptibility variants. Mol Psychiatry; e-pub ahead of print 3 January 2012.

Gaszner M, Felsenfeld G (2006). Insulators: exploiting transcriptional and epigenetic mechanisms. Nat Rev Genet 7: 703-713.

Gavin DP, Akbarian S (2011). Epigenetic and post-transcriptional dysregulation of gene expression in schizophrenia and related disease. Neurobiol Dis 46: 255-262.

Gavin DP, Kartan S, Chase K, Grayson DR, Sharma RP (2008). Reduced baseline acetylated histone 3 levels, and a blunted response to HDAC inhibition in lymphocyte cultures from schizophrenia subjects. Schizophr Res 103: 330-332.

Gavin DP, Kartan S, Chase K, Jayaraman S, Sharma RP (2009). Histone deacetylase inhibitors and candidate gene expression: An in vivo and in vitro approach to studying chromatin remodeling in a clinical population. $J$ Psychiatr Res 43: 870-876.

Gavin DP, Sharma RP, Chase KA, Matrisciano F, Dong E, Guidotti A (2012). Growth arrest and DNA-damage-inducible, beta (GADD45b)-mediated DNA demethylation in major psychosis. Neuropsychopharmacology 37: 531-542.

Gertz J, Varley KE, Reddy TE, Bowling KM, Pauli F, Parker SL et al (2011). Analysis of DNA methylation in a three-generation family reveals widespread genetic influence on epigenetic regulation. PLoS Genet 7: e1002228.

Grayson DR, Jia X, Chen Y, Sharma RP, Mitchell CP, Guidotti A et al (2005). Reelin promoter hypermethylation in schizophrenia. Proc Natl Acad Sci USA 102: 9341-9346.

Guidotti A, Auta J, Davis JM, Di-Giorgi-Gerevini V, Dwivedi Y, Grayson DR et al (2000). Decrease in reelin and glutamic acid decarboxylase67 (GAD67) expression in schizophrenia and bipolar disorder: a postmortem brain study. Arch Gen Psychiatry 57: 1061-1069.

Guidotti A, Dong E, Kundakovic M, Satta R, Grayson DR, Costa E (2009). Characterization of the action of antipsychotic subtypes on valproate-induced chromatin remodeling. Trends Pharmacol Sci 30: 55-60.

Guo JU, Ma DK, Mo H, Ball MP, Jang MH, Bonaguidi MA et al (2011). Neuronal activity modifies the DNA methylation landscape in the adult brain. Nat Neurosci 14: 1345-1351.

Haroutunian V, Katsel P, Dracheva S, Stewart DG, Davis KL (2007). Variations in oligodendrocyte-related gene expression across multiple cortical regions: implications for the pathophysiology of schizophrenia. Int J Neuropsychopharmacol 10: 565-573.

Hayashi Y, Nihonmatsu-Kikuchi N, Yu X, Ishimoto K, Hisanaga SI, Tatebayashi Y (2011). A novel, rapid, quantitative cell-counting method reveals oligodendroglial reduction in the frontopolar cortex in major depressive disorder. Mol Psychiatry 16: $1155-1158$.

Hernandez DG, Nalls MA, Gibbs JR, Arepalli S, van der Brug M, Chong S et al (2011). Distinct DNA methylation changes highly correlated with chronological age in the human brain. Hum Mol Genet 20: 1164-1172.

Horike S, Cai S, Miyano M, Cheng JF, Kohwi-Shigematsu T (2005). Loss of silentchromatin looping and impaired imprinting of DLX5 in Rett syndrome. Nat Genet 37: $31-40$

Hsieh J, Nakashima K, Kuwabara T, Mejia E, Gage FH (2004). Histone deacetylase inhibition-mediated neuronal differentiation of multipotent adult neural progenitor cells. Proc Natl Acad Sci USA 101: 16659-16664.

Huang HS, Akbarian S (2007a). GAD1 mRNA expression and DNA methylation in prefrontal cortex of subjects with schizophrenia. PLoS One 2: e809.

Huang HS, Matevossian A, Jiang Y, Akbarian S (2006). Chromatin immunoprecipitation in postmortem brain. J Neurosci Methods 156: 284-292.

Huang HS, Matevossian A, Whittle C, Kim SY, Schumacher A, Baker SP et al (2007b). Prefrontal dysfunction in schizophrenia involves mixed-lineage leukemia 1-regulated histone methylation at GABAergic gene promoters. J Neurosci 27: 11254-11262.
Huangfu D, Osafune K, Maehr R, Guo W, Eijkelenboom A, Chen S et al (2008). Induction of pluripotent stem cells from primary human fibroblasts with only Oct4 and Sox2. Nat Biotechnol 26: 1269-1275.

Iwamoto K, Bundo M, Ueda J, Oldham MC, Ukai W, Hashimoto E et al (2011). Neurons show distinctive DNA methylation profile and higher interindividual variations compared with non-neurons. Genome Res 21: 688-696.

Iwamoto K, Bundo M, Yamada K, Takao H, Iwayama-Shigeno Y, Yoshikawa T et al (2005). DNA methylation status of SOX10 correlates with its downregulation and oligodendrocyte dysfunction in schizophrenia. J Neurosci 25: 5376-5381.

Jiang Y, Jakovcevski M, Bharadwaj R, Connor C, Schroeder FA, Lin CL et al (2010). Setdb1 histone methyltransferase regulates mood-related behaviors and expression of the NMDA receptor subunit NR2B. J Neurosci 30: 7152-7167.

Jiang Y, Matevossian A, Huang HS, Straubhaar J, Akbarian S (2008). Isolation of neuronal chromatin from brain tissue. BMC Neurosci 9: 42

Jin C, Felsenfeld G (2007). Nucleosome stability mediated by histone variants $\mathrm{H} 3.3$ and H2A.Z. Genes Dev 21: 1519-1529.

Jin SG, Wu X, Li AX, Pfeifer GP (2011). Genomic mapping of 5-hydroxymethylcytosine in the human brain. Nucleic Acids Res 39: 5015-5024.

Kaminsky ZA, Tang T, Wang SC, Ptak C, Oh GH, Wong AH et al (2009). DNA methylation profiles in monozygotic and dizygotic twins. Nat Genet 41: 240-245.

Kent WJ (2002). BLAT-the BLAST-like alignment tool. Genome Res 12: 656-664.

Kim KS (2010). Induced pluripotent stem (iPS) cells and their future in psychiatry. Neuropsychopharmacology 35: 346-348.

Kinney SM, Chin HG, Vaisvila R, Bitinaite J, Zheng Y, Esteve PO et al (2011). Tissuespecific distribution and dynamic changes of 5-hydroxymethylcytosine in mammalian genomes. J Biol Chem 286: 24685-24693.

Kleinjan DA, van Heyningen V (2005). Long-range control of gene expression: emerging mechanisms and disruption in disease. Am J Hum Genet 76: 8-32.

Klose RJ, Zhang Y (2007). Regulation of histone methylation by demethylimination and demethylation. Nat Rev Mol Cell Biol 8: 307-318.

Kouzarides T (2007). Chromatin modifications and their function. Cell 128: 693-705.

Kriaucionis S, Heintz N (2009). The nuclear DNA base 5-hydroxymethylcytosine is present in Purkinje neurons and the brain. Science 324: 929-930.

Kundakovic M, Chen Y, Costa E, Grayson DR (2007). DNA methyltransferase inhibitors coordinately induce expression of the human reelin and glutamic acid decarboxylase 67 genes. Mol Pharmacol 71: 644-653.

Kwon B, Houpt TA (2010). Phospho-acetylation of histone H3 in the amygdala after acute lithium chloride. Brain Res 1333: 36-47.

Langmead B, Trapnell C, Pop M, Salzberg SL (2009). Ultrafast and memoryefficient alignment of short DNA sequences to the human genome. Genome Biol 10: R25.

LaPlant Q, Vialou V, Covington III HE, Dumitriu D, Feng J, Warren BL et al (2010). Dnmt3a regulates emotional behavior and spine plasticity in the nucleus accumbens. Nat Neurosci 13: 1137-1143.

Levenson JM, Roth TL, Lubin FD, Miller CA, Huang IC, Desai P et al (2006). Evidence that DNA (cytosine-5) methyltransferase regulates synaptic plasticity in the hippocampus. J Biol Chem 281: 15763-15773.

Li G, Reinberg D (2011a). Chromatin higher-order structures and gene regulation. Curr Opin Genet Dev 21: 175-186.

Li H, Zhong X, Chau KF, Williams EC, Chang Q (2011b). Loss of activity-induced phosphorylation of MeCP2 enhances synaptogenesis, LTP and spatial memory. Nat Neurosci 14: 1001-1008.

Li J, Guo Y, Schroeder FA, Youngs RM, Schmidt TW, Ferris C et al (2004). Dopamine D2-like antagonists induce chromatin remodeling in striatal neurons through cyclic AMP-protein kinase A and NMDA receptor signaling. J Neurochem 90: 1117-1131.

Lin M, Pedrosa E, Shah A, Hrabovsky A, Maqbool S, Zheng D et al (2011). RNA-Seq of human neurons derived from iPS cells reveals candidate long non-coding RNAs involved in neurogenesis and neuropsychiatric disorders. PLoS One 6: e23356.

Loenarz C, Schofield CJ (2011). Physiological and biochemical aspects of hydroxylations and demethylations catalyzed by human 2-oxoglutarate oxygenases. Trends Biochem Sci 36: 7-18.

Lomvardas S, Barnea G, Pisapia DJ, Mendelsohn M, Kirkland J, Axel R (2006). Interchromosomal interactions and olfactory receptor choice. Cell 126: 403-413.

Ma DK, Jang MH, Guo JU, Kitabatake Y, Chang ML, Pow-Anpongkul N et al (2009). Neuronal activity-induced Gadd45b promotes epigenetic DNA demethylation and adult neurogenesis. Science 323: 1074-1077.

Marenco S, Savostyanova AA, van der Veen JW, Geramita M, Stern A, Barnett AS et al (2010). Genetic modulation of GABA levels in the anterior cingulate cortex by GAD1 and COMT. Neuropsychopharmacology 35: 1708-1717.

Martinowich K, Hattori D, Wu H, Fouse S, He F, Hu Y et al (2003). DNA methylationrelated chromatin remodeling in activity-dependent BDNF gene regulation. Science 302: 890-893. 
Marutha Ravindran CR, Ticku MK (2004). Changes in methylation pattern of NMDA receptor NR2B gene in cortical neurons after chronic ethanol treatment in mice. Brain Res Mol Brain Res 121: 19-27.

Matevossian A, Akbarian S (2008). Neuronal nuclei isolation from human postmortem brain tissue. J Vis Exp (20): pii:914. doi: 10.3791/914.

Maunakea AK, Nagarajan RP, Bilenky M, Ballinger TJ, D'Souza C, Fouse SD et al (2010). Conserved role of intragenic DNA methylation in regulating alternative promoters. Nature 466: 253-257.

McGowan PO, Sasaki A, D'Alessio AC, Dymov S, Labonte B, Szyf M et al (2009). Epigenetic regulation of the glucocorticoid receptor in human brain associates with childhood abuse. Nat Neurosci 12: 342-348.

McGowan PO, Sasaki A, Huang TC, Unterberger A, Suderman M, Ernst C et al (2008). Promoter-wide hypermethylation of the ribosomal RNA gene promoter in the suicide brain. PLoS One 3: e2085.

Mellios N, Huang HS, Baker SP, Galdzicka M, Ginns E, Akbarian S (2009). Molecular determinants of dysregulated GABAergic gene expression in the prefrontal cortex of subjects with schizophrenia. Biol Psychiatry 65: 1006-1014.

Micsinai M, Parisi F, Strino F, Asp P, Dynlacht BD, Kluger Y (2012). Picking ChIP-seq peak detectors for analyzing chromatin modification experiments. Nucleic Acids Res; e-pub ahead of print 15 February 2012.

Mill J, Tang T, Kaminsky Z, Khare T, Yazdanpanah S, Bouchard L et al (2008). Epigenomic profiling reveals DNA-methylation changes associated with major psychosis. Am J Hum Genet 82: 696-711.

Miller BH, Zeier Z, Xi L, Lanz TA, Deng S, Strathmann J et al (2012). MicroRNA-132 dysregulation in schizophrenia has implications for both neurodevelopment and adult brain function. Proc Natl Acad Sci USA 109: 3125-3130.

Miller CA, Gavin CF, White JA, Parrish RR, Honasoge A, Yancey CR et al (2010). Cortical DNA methylation maintains remote memory. Nat Neurosci 13: 664-666.

Miller CA, Sweatt JD (2007). Covalent modification of DNA regulates memory formation. Neuron 53: 857-869.

Mirnics K, Pevsner J (2004). Progress in the use of microarray technology to study the neurobiology of disease. Nat Neurosci 7: 434-439.

Muotri AR, Marchetto MC, Coufal NG, Oefner R, Yeo G, Nakashima K et al (2010). L1 retrotransposition in neurons is modulated by MeCP2. Nature 468: 443-446.

Nelson ED, Kavalali ET, Monteggia LM (2008). Activity-dependent suppression of miniature neurotransmission through the regulation of DNA methylation. J Neurosci 28: 395-406.

Nishino K, Toyoda M, Yamazaki-Inoue M, Fukawatase Y, Chikazawa E, Sakaguchi $\mathrm{H}$ et al (2011). DNA methylation dynamics in human induced pluripotent stem cells over time. PLoS Genet 7: e1002085.

Nowak SJ, Corces VG (2004). Phosphorylation of histone H3: a balancing act between chromosome condensation and transcriptional activation. Trends Genet 20: 214-220.

Numachi Y, Shen H, Yoshida S, Fujiyama K, Toda S, Matsuoka H et al (2007). Methamphetamine alters expression of DNA methyltransferase $1 \mathrm{mRNA}$ in rat brain. Neurosci Lett 414: 213-217.

Numachi Y, Yoshida S, Yamashita M, Fujiyama K, Naka M, Matsuoka H et al (2004). Psychostimulant alters expression of DNA methyltransferase mRNA in the rat brain. Ann NY Acad Sci 1025: 102-109.

Numata S, Ye T, Hyde TM, Guitart-Navarro X, Tao R, Wininger M et al (2012). DNA methylation signatures in development and aging of the human prefrontal cortex. Am J Hum Genet 90: 260-272.

O'Roak BJ, Deriziotis P, Lee C, Vives L, Schwartz JJ, Girirajan S et al (2011). Exome sequencing in sporadic autism spectrum disorders identifies severe de novo mutations. Nat Genet 43: 585-589.

Oberle I, Rousseau F, Heitz D, Kretz C, Devys D, Hanauer A et al (1991). Instability of a 550-base pair DNA segment and abnormal methylation in fragile $X$ syndrome. Science 252: 1097-1102.

Ohi Y, Qin H, Hong C, Blouin L, Polo JM, Guo T et al (2011). Incomplete DNA methylation underlies a transcriptional memory of somatic cells in human iPS cells. Nat Cell Biol 13: 541-549.

Ooi SK, Bestor TH (2008). The colorful history of active DNA demethylation. Cell 133: 1145-1148.

Pang ZP, Yang N, Vierbuchen T, Ostermeier A, Fuentes DR, Yang TQ et al (2011). Induction of human neuronal cells by defined transcription factors. Nature 476: 220-223.

Park PJ (2009). ChIP-seq: advantages and challenges of a maturing technology. Nat Rev Genet 10: 669-680.

Pepke S, Wold B, Mortazavi A (2009). Computation for ChIP-seq and RNA-seq studies. Nat Methods 6(11 Suppl): S22-S32.

Purcell SM, Wray NR, Stone JL, Visscher PM, O'Donovan MC, Sullivan PF et al (2009). Common polygenic variation contributes to risk of schizophrenia and bipolar disorder. Nature 460: 748-752.
Rodriguez-Paredes M, Esteller M (2011). Cancer epigenetics reaches mainstream oncology. Nat Med 17: 330-339.

Rogaev El, Lukiw WJ, Lavrushina O, Rogaeva EA, St George-Hyslop PH (1994). The upstream promoter of the beta-amyloid precursor protein gene (APP) shows differential patterns of methylation in human brain. Genomics 22: 340-347.

Salnikow K, Zhitkovich A (2008). Genetic and epigenetic mechanisms in metal carcinogenesis and cocarcinogenesis: nickel, arsenic, and chromium. Chem Res Toxicol 21: 28-44.

Satta R, Maloku E, Zhubi A, Pibiri F, Hajos M, Costa E et al (2008). Nicotine decreases DNA methyltransferase 1 expression and glutamic acid decarboxylase 67 promoter methylation in GABAergic interneurons. Proc Natl Acad Sci USA 105: 16356-16361.

Schroeder FA, Penta KL, Matevossian A, Jones SR, Konradi C, Tapper AR et al (2008). Drug-induced activation of dopamine $D(1)$ receptor signaling and inhibition of class I/II histone deacetylase induce chromatin remodeling in reward circuitry and modulate cocaine-related behaviors. Neuropsychopharmacology 33: 2981-2992.

Sharma RP, Grayson DR, Guidotti A, Costa E (2005). Chromatin, DNA methylation and neuron gene regulation-the purpose of the package. J Psychiatry Neurosci 30: 257-263.

Shi J, Levinson DF, Duan J, Sanders AR, Zheng Y, Pe'er I et al (2009). Common variants on chromosome 6p22.1 are associated with schizophrenia. Nature 460: 753-757.

Shimabukuro M, Jinno Y, Fuke C, Okazaki Y (2006). Haloperidol treatment induces tissue- and sex-specific changes in DNA methylation: a control study using rats. Behav Brain Funct 2: 37.

Shulha HP, Cheung I, Whittle C, Wang J, Virgil D, Lin CL et al (2011). Epigenetic Signatures of Autism: Trimethylated H3K4 Landscapes in Prefrontal Neurons. Arch Gen Psychiatry 69: 314-324.

Siegmund KD, Connor CM, Campan M, Long TI, Weisenberger DJ, Biniszkiewicz D et al (2007). DNA methylation in the human cerebral cortex is dynamically regulated throughout the life span and involves differentiated neurons. PLoS One 2: $\mathrm{e} 895$.

Simonis M, Klous P, Splinter E, Moshkin Y, Willemsen R, de Wit E et al (2006). Nuclear organization of active and inactive chromatin domains uncovered by chromosome conformation capture-on-chip (4C). Nat Genet 38: 1348-1354.

Simonis M, Kooren J, de Laat W (2007). An evaluation of 3C-based methods to capture DNA interactions. Nat Methods 4: 895-901.

Skene PJ, Illingworth RS, Webb S, Kerr AR, James KD, Turner DJ et al (2010). Neuronal MeCP2 is expressed at near histone-octamer levels and globally alters the chromatin state. Mol Cell 37: 457-468.

Smith TF, Waterman MS (1981). Identification of common molecular subsequences. J Mol Biol 147: 195-197.

Song CX, Szulwach KE, Fu Y, Dai Q, Yi C, Li X et al (2011). Selective chemical labeling reveals the genome-wide distribution of 5-hydroxymethylcytosine. Nat Biotechnol 29: 68-72.

Stefansson H, Ophoff RA, Steinberg S, Andreassen OA, Cichon S, Rujescu D et al (2009). Common variants conferring risk of schizophrenia. Nature 460: 744-747.

Stevens SJ, van Ravenswaaij-Arts CM, Janssen JW, Klein Wassink-Ruiter JS, van Essen AJ, Dijkhuizen T et al (2011). MYT1L is a candidate gene for intellectual disability in patients with 2p25.3 (2pter) deletions. Am J Med Genet A 155A: 2739-2745.

Straub RE, Lipska BK, Egan MF, Goldberg TE, Callicott JH, Mayhew MB et al (2007a). Allelic variation in GAD1 (GAD67) is associated with schizophrenia and influences cortical function and gene expression. Mol Psychiatry 12: 854-869.

Straub RE, Lipska BK, Egan MF, Goldberg TE, Kleinman JE, Weinberger DR (2007b). Allelic variation in GAD1 (GAD67) is associated with schizophrenia and influences cortical function and gene expression. Mol Psychiatry 12: 854-869.

Sugawara H, Iwamoto K, Bundo M, Ueda J, Ishigooka J, Kato T (2011). Comprehensive DNA methylation analysis of human peripheral blood leukocytes and lymphoblastoid cell lines. Epigenetics 6: 508-515.

Sutcliffe EL, Parish IA, He YQ, Juelich T, Tierney ML, Rangasamy D et al (2009). Dynamic histone variant exchange accompanies gene induction in T cells. $\mathrm{Mol}$ Cell Biol 29: 1972-1986.

Takahashi K, Yamanaka S (2006). Induction of pluripotent stem cells from mouse embryonic and adult fibroblast cultures by defined factors. Cell 126: 663-676.

Tamura Y, Kunugi H, Ohashi J, Hohjoh H (2007). Epigenetic aberration of the human REELIN gene in psychiatric disorders. Mol Psychiatry 12: 519, 593-600.

Tan M, Luo H, Lee S, Jin F, Yang JS, Montellier E et al (2011). Identification of 67 histone marks and histone lysine crotonylation as a new type of histone modification. Cell 146: 1016-1028.

Tang B, Dean B, Thomas EA (2011). Disease- and age-related changes in histone acetylation at gene promoters in psychiatric disorders. Translational Psychiatr 1: e64; doi:10.1038/tp.2011.61 
Taqi MM, Bazov I, Watanabe H, Sheedy D, Harper C, Alkass K et al (2011). Prodynorphin CpG-SNPs associated with alcohol dependence: elevated methylation in the brain of human alcoholics. Addict Biol 16: 499-509.

Tassone F, Hagerman RJ, Gane LW, Taylor AK (1999). Strong similarities of the FMR1 mutation in multiple tissues: postmortem studies of a male with a full mutation and a male carrier of a premutation. Am J Med Genet 84: 240-244.

Taverna SD, Li H, Ruthenburg AJ, Allis CD, Patel DJ (2007). How chromatin-binding modules interpret histone modifications: lessons from professional pocket pickers. Nat Struct Mol Biol 14: 1025-1040.

Tochigi M, Iwamoto K, Bundo M, Komori A, Sasaki T, Kato N et al (2008). Methylation status of the reelin promoter region in the brain of schizophrenic patients. Biol Psychiatry 63: 530-533.

Tohgi H, Utsugisawa K, Nagane Y, Yoshimura M, Genda Y, Ukitsu M (1999). Reduction with age in methylcytosine in the promoter region -224 approximately -101 of the amyloid precursor protein gene in autopsy human cortex. Brain Res Mol Brain Res 70: 288-292.

Tolstorukov MY, Volfovsky N, Stephens RM, Park PJ (2011). Impact of chromatin structure on sequence variability in the human genome. Nat Struct $\mathrm{Mol} \mathrm{Biol} \mathbf{1 8}$ : 510-515.

Tsankova N, Renthal W, Kumar A, Nestler EJ (2007). Epigenetic regulation in psychiatric disorders. Nat Rev Neurosci 8: 355-367.

Veldic M, Caruncho HJ, Liu WS, Davis J, Satta R, Grayson DR et al (2004). DNAmethyltransferase $1 \mathrm{mRNA}$ is selectively overexpressed in telencephalic GABAergic interneurons of schizophrenia brains. Proc Natl Acad Sci USA 101: 348-353.

Veldic M, Guidotti A, Maloku E, Davis JM, Costa E (2005). In psychosis, cortical interneurons overexpress DNA-methyltransferase 1. Proc Natl Acad Sci USA 102: 2152-2157.

Volman V, Behrens MM, Sejnowski TJ (2011). Downregulation of parvalbumin at cortical GABA synapses reduces network gamma oscillatory activity. J Neurosci 31: $18137-18148$
Wernig M, Zhao JP, Pruszak J, Hedlund E, Fu D, Soldner F et al (2008). Neurons derived from reprogrammed fibroblasts functionally integrate into the fetal brain and improve symptoms of rats with Parkinson's disease. Proc Natl Acad Sci USA 105: $5856-5861$.

West RL, Lee JM, Maroun LE (1995). Hypomethylation of the amyloid precursor protein gene in the brain of an Alzheimer's disease patient. J Mol Neurosci 6: $141-146$.

Wood AJ, Severson AF, Meyer BJ (2010). Condensin and cohesin complexity: the expanding repertoire of functions. Nat Rev Genet 11: 391-404.

Woodcock CL (2006). Chromatin architecture. Curr Opin Struct Biol 16: 213-220.

Xin Y, Chanrion B, O'Donnell AH, Milekic M, Costa R, Ge Y et al (2012). MethylomeDB: a database of DNA methylation profiles of the brain. Nucleic Acids Res 40(Database issue): D1245-D1249.

Xu B, Roos JL, Dexheimer P, Boone B, Plummer B, Levy S et al (2011). Exome sequencing supports a de novo mutational paradigm for schizophrenia. Nat Genet 43: 864-868.

Yu IT, Park JY, Kim SH, Lee JS, Kim YS, Son H (2009). Valproic acid promotes neuronal differentiation by induction of proneural factors in association with $\mathrm{H} 4$ acetylation. Neuropharmacology 56: 473-480.

Zhang D, Cheng L, Badner JA, Chen C, Chen Q, Luo W et al (2010a). Genetic control of individual differences in gene-specific methylation in human brain. Am J Hum Genet 86: 411-419.

Zhang TY, Hellstrom IC, Bagot RC, Wen X, Diorio J, Meaney MJ (2010b). Maternal care and DNA methylation of a glutamic acid decarboxylase 1 promoter in rat hippocampus. J Neurosci 30: 13130-13137.

Zhao J, Grant SF (2011). Advances in whole genome sequencing technology. Curr Pharm Biotechnol 12: 293-305.

Zhou WW, Goren A, Bernstein BE (2011). Charting histone modifications and the functional organization of mammalian genomes. Nat Rev Genet 12: 7-18. 